\title{
LabMorfoQuiz: um Aplicativo Gamificado como Recurso para Aprendizagem em Cursos Superiores de Saúde
}

\author{
Luiz Fernando Andrade Matos - DOL/UFS - 1fam-@hotmail.com \\ Acácia Rodrigues Costa - DOL/UFS - acacia.ketly@gmail.com \\ Grazielle de Oliveira Siqueira - DMEL/UFS - grazisiqueira55@gmail.com \\ Jéssica Alves dos Santos Menezes - DMEL/UFS - jessicamenezes.alves@gmail.com \\ Danilo Ferreira Neves - PROCC/UFS - danilo.neves@ufs.br \\ Lidiany Cerqueira Santos - STIL/UFS - lidianycs@ufs.br
}

Resumo: Dispositivos móveis fazem parte do cotidiano dos estudantes, entretanto como recurso de aprendizagem ainda desafiam docentes e gestores a integrá-los ao ambiente educacional. A gamificação na educação permite o desenvolvimento da criatividade, imaginação, pensamento lógico e aprendizado lúdico. Diante disso, surgem propostas para adoção da gamificação, associada ao uso de dispositivos móveis, criando-se aplicativos com jogos digitais como estratégia para promover a aprendizagem ativa. Este artigo apresenta o projeto, desenvolvimento e avaliação do LabMorfoQuiz, um aplicativo móvel gamificado para apoiar estudantes de disciplinas iniciais de cursos da saúde na Universidade Federal de Sergipe. Para desenvolver o LabMorfoQuiz foi utilizada a plataforma App Inventor. Em um experimento para avaliação da jogabilidade e experiência do jogador, com participação de 30 discentes, estes consideraram o aplicativo fácil de jogar, declararam-se motivados, interessados e consideraram o conteúdo do jogo relevante.

Palavras-chave: Gamificação, Jogo Digital, Educação em Saúde, Informática em Saúde, Aprendizagem Móvel.

\section{LabMorfoQuiz: A Gamified App as a Resource for Higher Health Education}

Abstract: Mobile devices are part of students' daily life; however, as a learning resource they still challenge teachers and managers to integrate them into the educational environment. Gamification in education enables the development of creativity, imagination, logical thinking and playful learning. There are proposals for gamification adoption, associated with mobile devices, creating digital games apps as a strategy to promote active learning. This paper presents the design, development and evaluation of LabMorfoQuiz, a gamified mobile application to support students in initial subjects of health courses at the Federal University of Sergipe. To develop LabMorfoQuiz, the App Inventor platform was used. In an experiment to assess gameplay and player experience involving 30 students, they rated the app easy to play; felt motivated, interested, and found the game content relevant.

Keywords: Gamification, Digital Game, Health Education, Health Informatics, Mobile Learning.

\section{Introdução}

Os métodos de ensino atuais buscam formar profissionais habilitados para lidar com problemas complexos, com capacidade para resolver problemas em diferentes contextos e a habilidade de pensar de maneira independente. Segundo Piaget (1990), a 
adoção de jogos em sala é uma ferramenta eficaz para a prática do intelecto, já que utiliza a análise, a observação, a atenção, a imaginação, o vocabulário, a linguagem e outras dimensões próprias do ser humano. Jogos sempre despertaram interesse das pessoas e os jogos digitais são uma forma de entretenimento bastante popular entre públicos de todas as idades (FARDO, 2013). Os jogos sérios (serious games) são jogos utilizados, além do entretenimento, para apoio ao ensino, aprendizagem ou treinamentos, de modo a possibilitar a exploração de seus elementos em outros contextos(ALDRICH, 2005).

A exploração de elementos próprios de jogos em outros contextos para motivar e engajar pessoas ficou conhecida como gamificação (PRENSKY, 2007). A gamificação é um fenômeno em ascensão graças à popularização dos jogos e da capacidade de motivar a ação, resolver problemas e potencializar a aprendizagem em diversas áreas do conhecimento e da própria vida (FARDO, 2013). Nesse contexto, o jogador depara-se com uma situação de desafio recompensadora e divertida, a ludificação engaja o jogador a um nível emocional de forma a motivá-lo a concluir um desafio em específico (BURKE, 2015). Entende-se que a gamificação pode promover a reflexão e envolvimento, aprimorar a motivação e o engajamento, auxiliando no desenvolvimento de habilidades e competências essenciais para a formação profissional, como a imaginação, a criatividade e o raciocínio lógico (KAPP, 2012; MARTINS et al., 2018; TODA et al., 2017).

Com base nas ideias de aprendizagem gamificada, alinhando entretenimento e educação, surgiu a proposta de desenvolvimento do jogo LabMorfoQuiz. Este consiste em uma aplicação móvel gamificada para estudo de anatomia humana, histologia, citologia, embriologia, fisiologia e patologia.

O jogo LabMorfoQuiz foi concebido na disciplina Informática Aplicada à Saúde, que faz parte do currículo dos cursos da saúde da Universidade Federal de Sergipe (UFS) - Campus Lagarto. Nesta disciplina, os discentes foram estimulados a construir aplicativos para dispositivos móveis voltados para a área da saúde ou educação em saúde, utilizando a ferramenta App Inventor ${ }^{1}$, de acordo com a metodologia proposta por Santos et al. (2019). Como resultado, os próprios discentes apresentaram um aplicativo gamificado como recurso para apoiar os estudantes das turmas iniciais dos cursos da saúde no referido Campus. Estes cursos adotam metodologias ativas de ensino, que consistem em estratégias de ensino centradas nos discentes, de modo que estes se tornem agentes na construção de conhecimentos e competências, rompendo-se com formas rígidas e pré-estabelecidas de ensino e aprendizagem (MASSON, 2012). A gamificação por definição não é uma metodologia de aprendizagem ativa, contudo, pode ser utilizada como uma estratégia para aprendizagem ativa. Os discentes do primeiro ciclo, muitas vezes, nunca tiveram contato com essas metodologias e frequentemente encontram dificuldades para adaptar-se e estudar de forma independente, justificando-se assim, o desenvolvimento do LabMorfoQuiz.

O presente trabalho tem como objetivo descrever o projeto, desenvolvimento e avaliação do jogo educativo denominado LabMorfoQuiz. O artigo está organizado da seguinte maneira: a Seção 2 detalha a metodologia utilizada para o desenvolvimento e avaliação; a Seção 3 apresenta os resultados obtidos; a Seção 4 expõe as ameaças à validade e na Seção 5 são apresentadas as considerações finais e trabalhos futuros.

1 http://ai2.appinventor.mit.edu/ V. $17 \mathrm{~N}^{\circ} 3$, dezembro, 2019 DOI: 


\section{Metodologia}

Para o desenvolvimento do LabMorfoQuiz, foi adotado o processo de design proposto por Rocha e Araujo (2013). Este processo é composto por três principais fases: pré-produção (planejamento), produção (análise, projeto, implementação, integração e teste), e pós-produção (execução e avaliação dos resultados).

O projeto LabMorfoQuiz foi concebido durante a disciplina Informática Aplicada à Saúde, na qual os discentes deveriam propor e construir aplicativos para dispositivos móveis voltados para a área da saúde ou educação em saúde, utilizando a ferramenta App Inventor (SANTOS et al., 2019; SANTOS et al., 2018). Após o fim da disciplina, o projeto foi continuado e aprovado em Edital de Extensão, financiado pela Pró-Reitoria de Extensão da UFS.

\subsection{Planejamento}

Pela experiência adquirida como estudantes e monitores do Laboratório Morfofuncional, os discentes escolheram este módulo para criação do jogo. O conteúdo da aplicação abrange conceitos de anatomia humana, histologia, citologia, embriologia, fisiologia e patologia. Compõem o Laboratório Morfofuncional sete disciplinas: Introdução à Ciência da Saúde (120h); Abrangência das Ações em Saúde (90h); Proliferação Celular, Inflamação e Infecção (120h); Percepção, Consciência e Emoção (120h); Concepção e Formação do Ser Humano (120h); Funções Biológicas, Metabolismo (120h). As disciplinas deste laboratório fazem parte da grade curricular do primeiro ciclo os 8 cursos do Campus Lagarto: Medicina, Enfermagem, Fisioterapia, Farmácia, Odontologia, Terapia Ocupacional, Fonoaudiologia e Nutrição, sendo obrigatória para todos os estudantes do Campus. As atividades do Laboratório Morfofuncional são desenvolvidas por meio de metodologias ativas.

O jogo foi planejado em forma de quiz. Para elaboração das questões foi realizado o levantamento bibliográfico das disciplinas. Fotografias de modelos, peças anatômicas e lâminas foram coletadas no próprio laboratório da disciplina para compor a aplicação.

\subsection{Produção}

Após o levantamento bibliográfico e planejamento do jogo, iniciou-se a fase de desenvolvimento. Com base no referencial bibliográfico das disciplinas, os próprios discentes criaram 176 questões, cada uma com quatro alternativas, sendo apenas uma correta. As questões foram separadas por disciplinas e novas questões podem ser adicionadas a base de dados do jogo caso se julgue necessário.

O jogo foi desenvolvido na plataforma App Inventor, adotada na disciplina de Informática Aplicada à Saúde por ser um ambiente de programação visual intuitivo, que facilita o desenvolvimento de aplicativos funcionais para programadores iniciantes (GROVER et al, 2015). O App Inventor possibilita a prática de programação gráfica baseada em blocos lógicos, sem uma linguagem de programação específica (WOLBER, 2014). Devido ao baixo grau de complexidade da plataforma, pessoas com pouca experiência em programação podem criar seus próprios projetos. O App Inventor é uma plataforma de código aberto, desenvolvida pelo Google e mantida pelo Massachusetts Institute of Technology (MIT). A ferramenta pode ser usada em um navegador web e todos os projetos ficam disponíveis na nuvem. Para ter acesso à ferramenta é necessário criar ou vincular a plataforma à uma conta do Google. 
O desenvolvimento de um projeto no App Inventor tem como base a criação das telas da aplicação, seguida da programação baseada em blocos lógicos. A ferramenta apresenta dois ambientes separados: Designer e Blocos. No ambiente de design, é possível criar visualmente a interface do usuário, clicando e arrastando os componentes da Paleta, como botões, legendas, imagens, sons, entre outros para o Visualizador. Na Figura 1, é apresentado o desenvolvimento de uma das telas do LabMorfoQuiz no ambiente Designer do App Inventor.

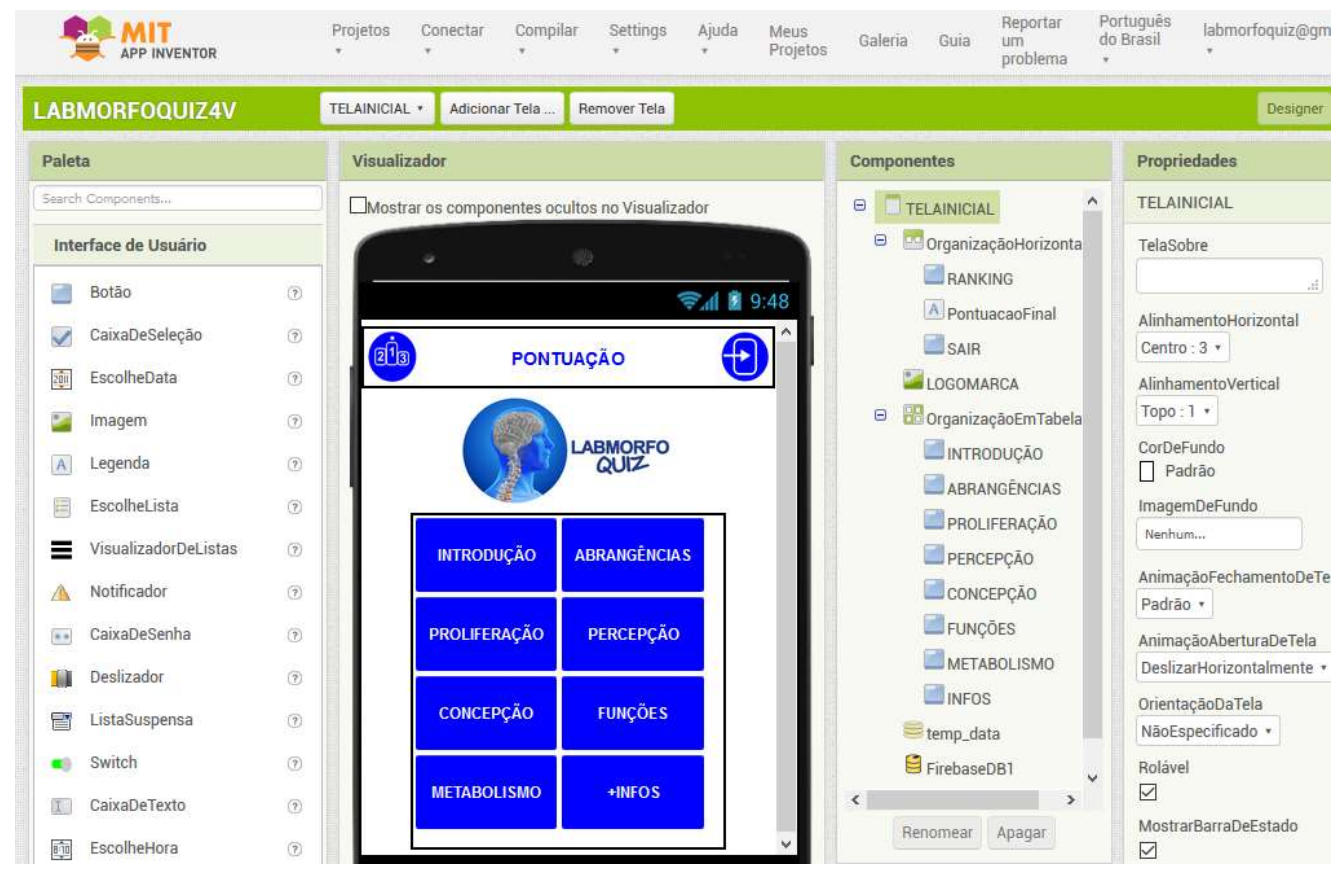

Figura 1 - Desenvolvimento da Interface de Usuário do LabMorfoQuiz no App Inventor.

No ambiente de Blocos, é possível controlar o comportamento dos componentes definidos anteriormente no ambiente de Designer. Para isso, o usuário dispõe de blocos conectáveis, que podem ser eventos ou procedimentos, variáveis, strings, listas, estruturas de controle, entre outros, com uma interface que permite arrastar e soltar. Na Figura 2, é apresentado o uso do ambiente Blocos do App Inventor para programação do comportamento dos componentes do LabMorfoQuiz.

Para persistência dos dados da aplicação, como perguntas, respostas, imagens do jogo, a pontuação dos jogadores e contas de usuário, foi utilizado um plano gratuito do Firebase $^{2}$. O Firebase é uma plataforma criada sobre a infraestrutura do Google que oferece uma opção para execução do back-end para dispositivos móveis sem a necessidade de gerenciar a infraestrutura de servidores. Para o armazenamento e sincronização dos dados do LabMorfoQuiz, foi utilizado o Firebase Realtime Database no qual os dados são armazenados em formato JSON e sincronizados em tempo real com todos os clientes conectados. Além da base de dados, o Firebase fornece o serviço de back-end para autenticar usuários na aplicação por meio de email e senha. Com este serviço, foi possível gerenciar as contas de usuário no jogo, armazenar a pontuação de cada jogador e criar um ranking de usuários. 


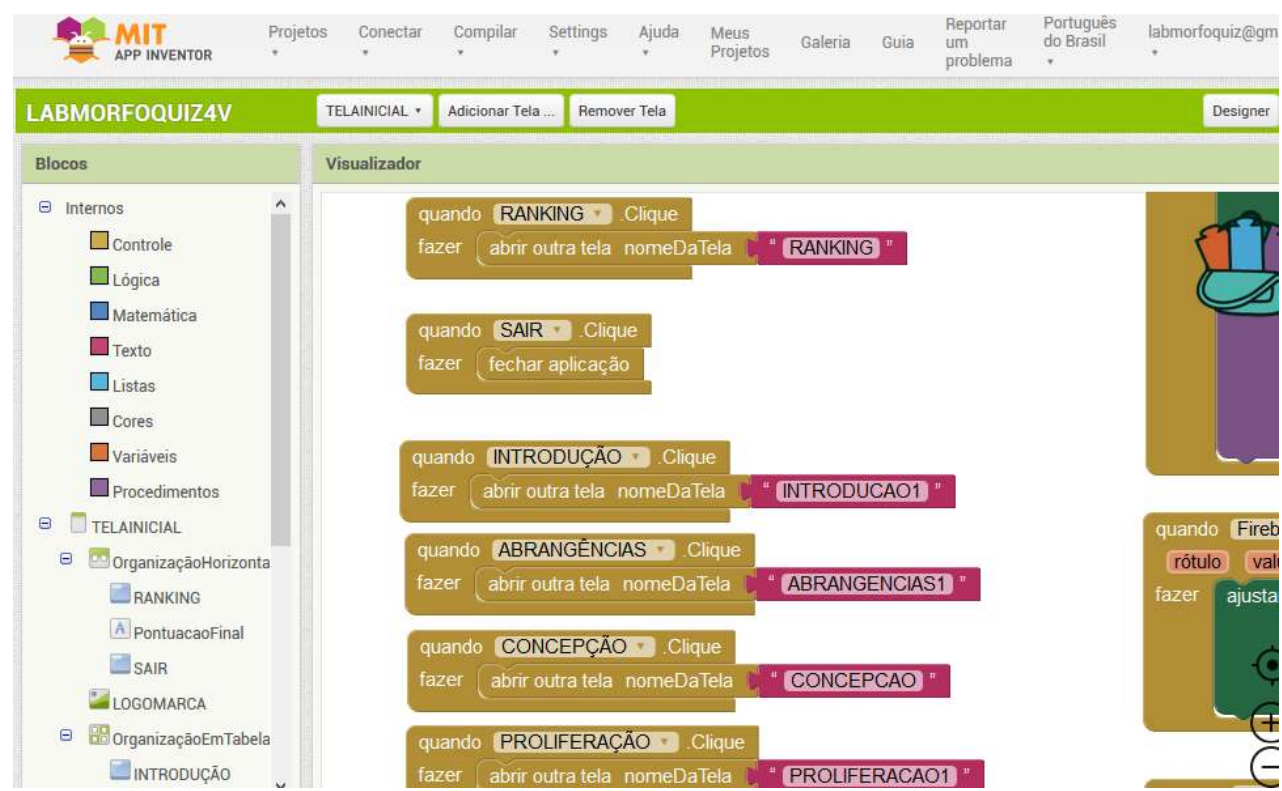

Figura 2 - Programação em blocos do LabMorfoQuiz no App Inventor.

\subsection{Avaliação}

Para avaliação do LabMorfoQuiz, foi adotado o modelo MEEGA+ (PETRI et al, 2018). Este modelo foi escolhido por fornecer um kit pronto para uso (incluindo um questionário e uma planilha de análise) para avaliação da qualidade de jogos educativos. A avaliação do jogo com o referido modelo foi realizada no dia 09 de outubro de 2019 , junto a um grupo de 30 discentes do Campus Lagarto. Os discentes participantes da avaliação foram convidados a utilizar o aplicativo durante 5 minutos e em seguida, a responder o questionário com 31 perguntas seguindo a escala Likert de 5 pontos, variando de -2 (discordo fortemente) a 2 (concordo fortemente) e 3 questões abertas.

Na próxima seção, são apresentados os resultados alcançados com o desenvolvimento e a avaliação do aplicativo.

\section{Resultados}

O aplicativo LabMorfoQuiz foi desenvolvido com uma interface intuitiva e de fácil utilização. Ao abrir o aplicativo o usuário é apresentado à tela de autenticação, na qual é possível entrar com email e senha, cadastrar uma nova conta ou redefinir a senha (Figura 3). Ao cadastrar uma nova conta, o usuário deverá informar email e senha, o email será usado posteriormente caso o jogador esqueça e deseje redefinir a senha e também para identificar o jogador no ranking. Todas estas operações são realizadas de modo automático, em tempo real, com uso do Firebase Authentication e permitem que o usuário comece a utilizar o jogo imediatamente.

Após a autenticação o jogador será apresentado à tela inicial do jogo, na qual poderá escolher qualquer módulo do Laboratório Morfofuncional para jogar (Figura 4). Ao escolher um módulo, o jogo irá carregar uma questão aleatoriamente contendo 4 alternativas, sendo apenas 1 correta. Um contador regressivo de 30 segundos é iniciado a cada questão. O jogador terá esse tempo para responder e irá marcar entre 5 a 20 pontos de acordo com o tempo de resposta. Caso erre ou não responda, o jogador perderá 5 pontos. O total de questões apresentadas em cada rodada de jogo varia entre os módulos. Ao fim de uma rodada de questões, o jogador poderá continuar no mesmo módulo, passar para o seguinte ou voltar a tela inicial. O jogador poderá interromper uma rodada de 
questões clicando no botão voltar do celular a qualquer momento e a pontuação atual será salva.
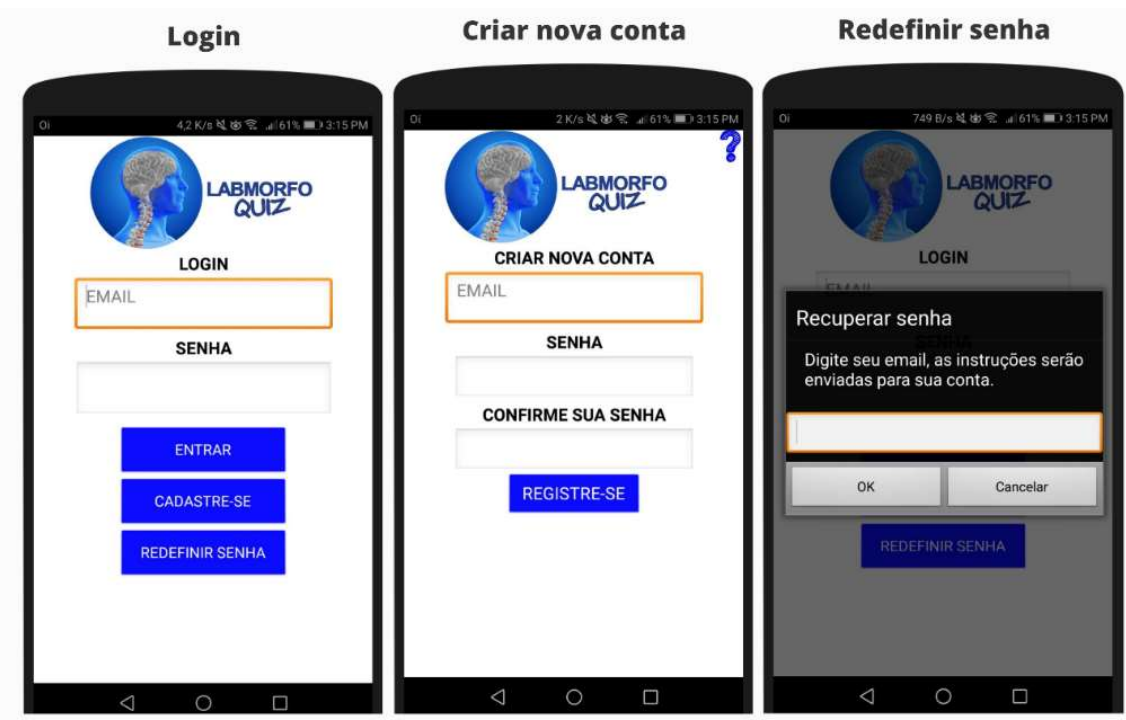

Figura 3 - Telas de autenticação, criação de nova conta e redefinição de senha do LabMorfoQuiz

Ao acertar uma questão, o aplicativo toca um som sinalizando o acerto e marca a resposta com a cor verde. Ao errar, o jogo toca um som notificando o erro e marca a resposta em vermelho. Os áudios para o jogo foram obtidos de forma gratuita nas plataformas Sound Bible ${ }^{3}$ e Free Sound ${ }^{4}$. O ícone do aplicativo foi obtido na plataforma Freepik ${ }^{5}$.
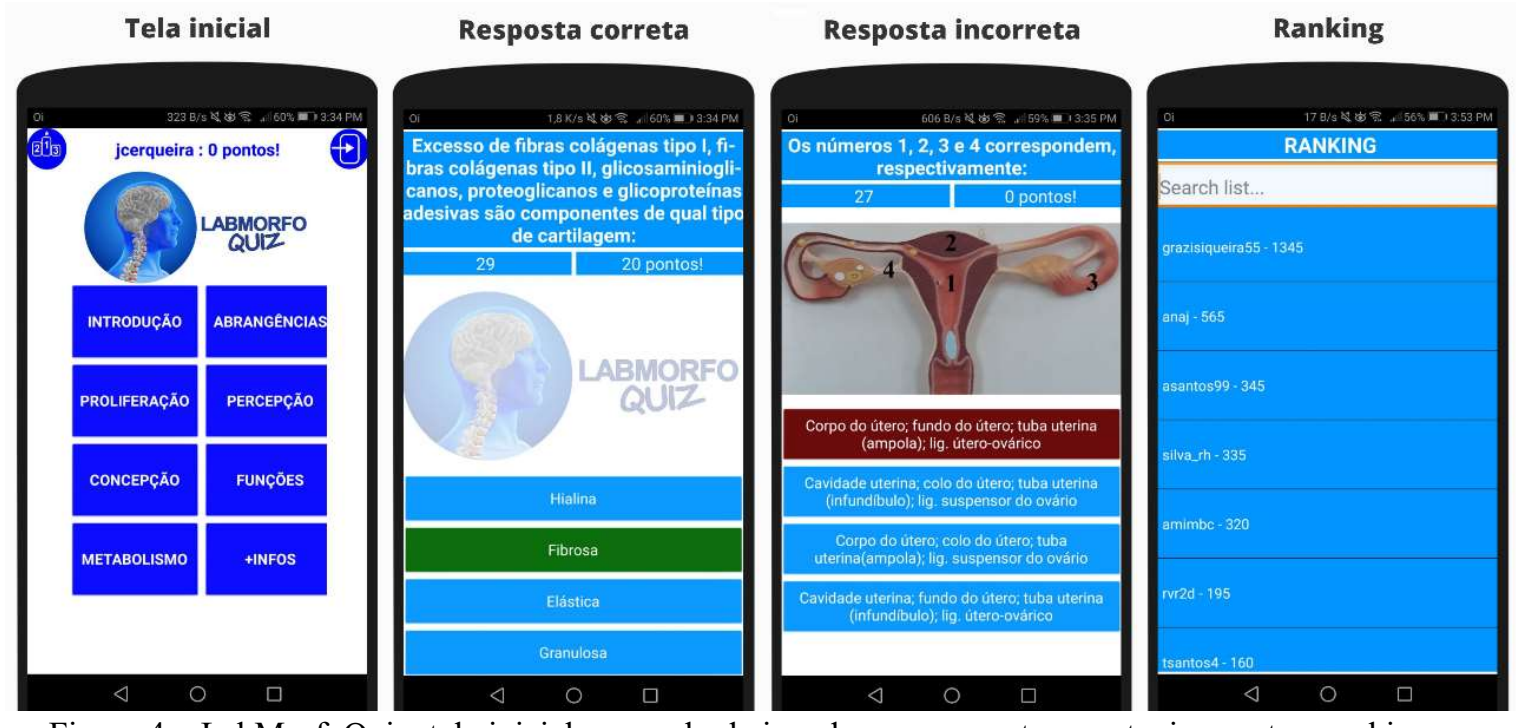

Figura 4 - LabMorfoQuiz: tela inicial, exemplo de jogada com resposta correta, incorreta e ranking.

Com objetivo de avaliar o jogo em termos de experiência do jogador e usabilidade, do ponto de vista dos discentes, foi realizado um experimento e utilizado o questionário

\footnotetext{
${ }^{3}$ http://soundbible.com/

${ }^{4}$ https://freesound.org/

5 https://br.freepik.com/

V. $17 \mathrm{~N}^{\circ}$ 3, dezembro, 2019
} DOI: 
do modelo MEEGA+ (PETRI et al., 2018). Os dados coletados foram analisados usando estatística descritiva em termos de distribuição de frequência e tendência central (mediana).

O experimento foi realizado em uma sala reservada sob supervisão dos pesquisadores. Os testes do aplicativo foram realizados em dispositivos pré-selecionados. $\mathrm{O}$ experimento foi executado em turnos, a cada turno um grupo de participantes era inserido na sala. Os participantes testaram o aplicativo por 5 minutos e depois responderam ao questionário.

Participaram da avaliação 30 estudantes, selecionados de modo aleatório, com idade entre 18 a 28 anos, sendo 13 do sexo feminino e 17 do sexo masculino. Dentre os 30 participantes, a maioria (40\%) relatou que costuma usar jogos digitais diariamente, $27 \%$ jogam raramente, $20 \%$ jogam semanalmente, $10 \%$ ao menos uma vez ao mês e, $3 \%$ nunca jogam.

Em termos de usabilidade (Figura 5), todos os itens tiveram avaliação positiva dos discentes, que consideraram fácil aprender a jogar, as regras claras e bastante compreensíveis, o design atraente e consistente, as cores, imagens e fontes legíveis e compreensíveis.

Seguindo o modelo MEEGA+, a experiência proporcionada aos jogadores foi avaliada em termos de confiança, desafio, satisfação, interação social, diversão, atenção focada, relevância e percepção de aprendizagem. Analisando os dados coletados, identificou-se de forma geral que o LabMorfoQuiz proporcionou uma experiência positiva aos estudantes, especialmente em termos de confiança, satisfação, relevância e percepção de aprendizagem (Figura 6). O conteúdo do jogo foi considerado relevante e alinhado à disciplina, contribuindo para relembrar os conceitos apresentados no Laboratório Morfofuncional. Os participantes relataram se sentir desafiados e satisfeitos, além de indicar que recomendariam o jogo aos colegas. No entanto, identificou-se que os itens relacionados a interação social, tiveram uma avaliação mais baixa, o que pode ser consequência da falta de interação entre os estudantes durante o experimento devido ao tempo limitado para sua realização e da interação no aplicativo estar limitada ao ranking, indicando uma possibilidade de melhoria neste aspecto.

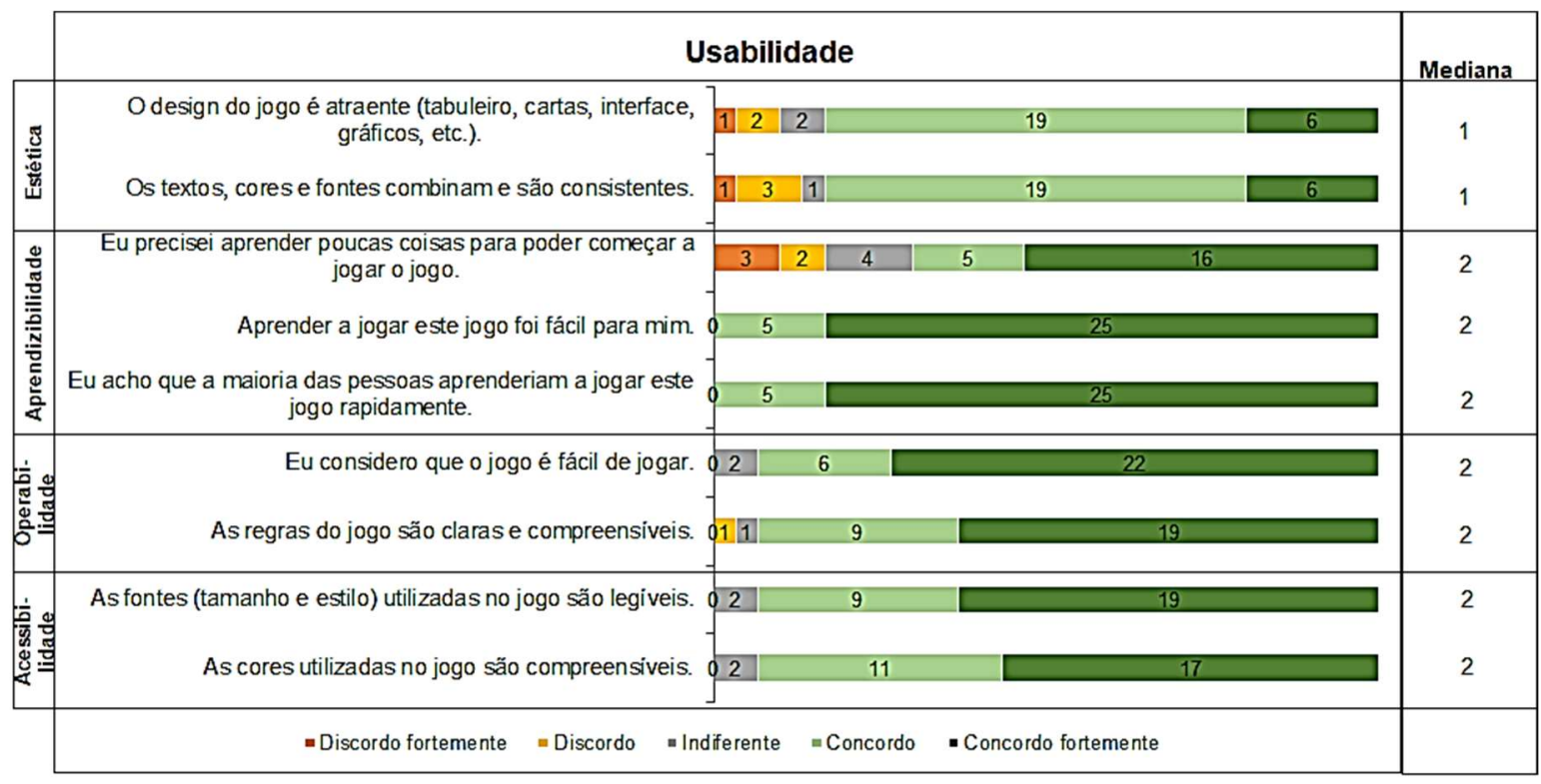

Figura 5 - Resultado da avaliação de usabilidade do LabMorfoQuiz com base no total de 30 respostas. V. $17 \mathrm{~N}^{\mathrm{o}} 3$, dezembro, 2019 DOI: 


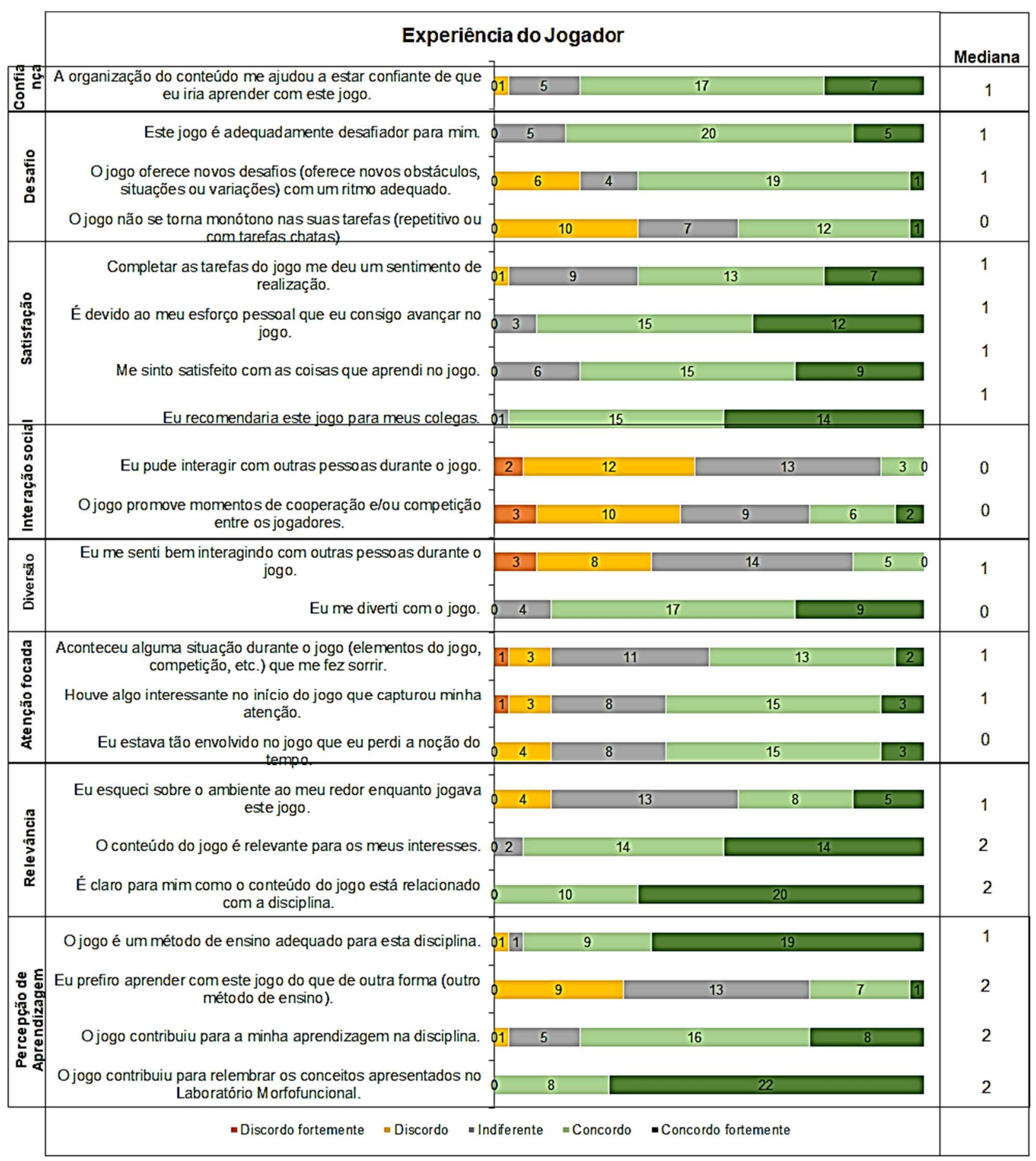

Figura 6 - Resultado da avaliação da experiência do jogador baseado no total de 30 respostas.

Nas questões subjetivas, os discentes tiveram espaço para discutir pontos fortes e propor melhorias para o aplicativo. Dentre os pontos fortes, foram citadas a qualidade das imagens utilizadas no jogo, a relação do conteúdo com a disciplina, a dinâmica do jogo e a motivação para responder rapidamente as perguntas. Como sugestão de melhoria, alguns estudantes apontaram a possibilidade de aumentar o número de questões por módulo, pois segundo eles, algumas questões se repetiram durante o experimento. Alguns participantes questionaram o fato de o jogo não indicar a alternativa correta quando o jogador comete um erro. Outra sugestão apresentada pelos discentes foi adicionar níveis de dificuldade ao jogo.

V. $17 \mathrm{~N}^{\circ}$ 3, dezembro, 2019

DOI: 


\section{Ameaças à Validade}

- Validade de Construção: o aplicativo foi desenvolvido por uma equipe multidisciplinar formada por discentes com experiência prática na disciplina que consiste no foco de atuação da ferramenta, como estudantes e monitores. Ademais, a equipe conta com dois profissionais da área de tecnologia que participaram de todo o processo de planejamento e desenvolvimento do aplicativo.

- Validade Interna: o jogo foi avaliado com auxílio de um modelo apropriado para o escopo da ferramenta. O MEEGA+ é um modelo próprio para avaliação de jogos educacionais testado e validado.

- Validade Externa: os participantes do experimento foram selecionados aleatoriamente apenas para avaliação da ferramenta, não tendo relação com o projeto do aplicativo. Estes são alunos da própria instituição que efetivamente conhecem e participaram da disciplina foco do aplicativo. Uma sala foi reservada para avaliação, simulando um ambiente de aula. O teste foi supervisionado para que os participantes não perdessem o foco da avaliação. $\mathrm{O}$ experimento foi realizado em turnos, com grupos restritos a cada rodada, reduzindo a quantidade de participantes ao mesmo tempo na sala de aula e permitindo um maior controle do relacionamento entre os participantes.

\section{Conclusão e Trabalhos Futuros}

Esse estudo teve como objetivo apresentar o desenvolvimento e a avaliação do aplicativo LabMorfoQuiz, um jogo para auxiliar os discentes do primeiro ciclo de cursos da saúde na aprendizagem do Laboratório Morfofuncional. A iniciativa do projeto surgiu a partir da metodologia de ensino adotada na disciplina de Informática Aplicada à Saúde (SANTOS et al., 2019; SANTOS et al., 2018). O aplicativo foi desenvolvido por discentes dos cursos de odontologia e medicina, que após cursar a referida disciplina demonstraram interesse em aperfeiçoar o aplicativo e avaliaram positivamente a experiência de atuar como projetistas e desenvolvedores, bem como a utilização do App Inventor, por ser uma plataforma intuitiva e não exigir conhecimentos avançados de programação.

De acordo com avaliação do jogo, realizada com base no modelo MEEGA+ (PETRI et al, 2019), os discentes consideraram a experiência positiva, classificando o jogo como intuitivo, fácil de usar e com bom conteúdo para auxiliar no ensino e aprendizagem do Laboratório Morfofuncional. Deste modo, entende-se que o jogo LabMorfoQuiz pode ser um bom recurso para engajar e motivar os estudantes, consequentemente gerando melhores resultados. Com isso, pretende-se futuramente disponibilizar o aplicativo para que seja integrado ao plano pedagógico dos cursos do campus, oferecendo uma opção de aprendizagem lúdica e divertida aos discentes. Pretende-se ainda, realizar o registro do software por meio da Coordenação de Inovação e Transferência de Tecnologia (CINTTEC) da universidade.

\section{Agradecimentos}

Aos discentes do Campus Lagarto que concordaram em participar da pesquisa de avaliação de qualidade do jogo e à Pró-Reitoria de Extensão (PROEX) da UFS pelas bolsas de extensão (Edital Nº 23/2018) que viabilizaram a conclusão do projeto. 


\section{Referências}

ALDRICH, C. "Learning by doing: a comprehensive guide to simulations, computer games, and pedagogy in e-learning and other educational experiences". San Francisco: Pfeiffer, 2005.

BURKE, B. Gameficar: Como a gamificação motiva as pessoas a fazerem coisas extraordinárias, $1^{\text {o }}$ ed., São Paulo: DVS, 2015.

FARDO, M. L. A gamificação aplicada em ambientes de aprendizagem. RENOTE, v. 11, n. 1, 2013.

GROVER, S., PEA, R., COOPER, S. Designing for deeper learning in a blended computer science course for middle school students. Journal Computer Science Education, 25(2), 199-237, 2015

KAPP, K. M. The gamification of learning and instruction: game based methods and strategies for training and education. John Wiley \& Sons, 2012.

MARTINS, C.; GIRAFFA, L. M. M.; DO ROSÁRIO LIMA, V. M., Gamificação e seus potenciais como estratégia pedagógica no Ensino Superior. RENOTE, v. 16, n. 1, 2018.

MASSON, T. J.; et al. Metodologia de ensino: aprendizagem baseada em projetos (pbl). In: Anais do XL Congresso Brasileiro de Educação em Engenharia (COBENGE), Belém, PA, Brasil. [s.1.]: sn, 2012.

PETRI, G.; VON WANGENHEIM, C.G.; BORGATTO, A. F. MEEGA+, Systematic Model to Evaluate Educational Games. Encyclopedia of Computer Graphics and Games. 2018.

PIAGET, J. A formação do símbolo na criança-Imitação. Jogo e Sonho, Imagem e Representação. Rio de Janeiro: LTC, 1990.

PRENSKY, M. Digital Game-Based Learning, 2º ed., Paragon House, 2007.

ROCHA, R. V.; ARAUJO, R. B. Metodologia de Design de Jogos Sérios para Treinamento: Ciclo de vida de criação, desenvolvimento e produção. XII Simpósio Brasileiro de Jogos e Entretenimento Digital (SBGames 2013), p. 1-10, 2013.

SANTOS, L. C; Neves, D. F.; de Moura Filho, H. C.; dos Santos Menezes, F.; da Silva, L. F. S. Prototipação de Aplicativos como Método de Aprendizagem na Informática em Saúde: Um Relato de Experiência. In: Anais do Workshop de Informática na Escola. p. $90,2018$.

SANTOS, L. C.; Neves, D. F.; de Moura Filho, H. C.; dos Santos Menezes, F. Aprendizagem Baseada em Projetos na Informática em Saúde: Desenvolvendo Aplicativos com App Inventor. RENOTE, v. 17, n. 1, p. 42-51, 2019.

TODA, A. M.; DA SILVA, A. P.; ISOTANI, S. Desafios para o Planejamento e Implantação da Gamificação no Contexto Educacional. RENOTE, v. 15, n. 2, 2017.

WOLBER, D.; ABELSON, H.; FRIEDMAN, M. Democratizing computing with App Inventor. Get Mobile, 18(4), 53-58, 2014. 